\title{
Research related to application of 3D printing technique in educational military equipment
}

\author{
Zibin Zhang, Xiaopeng Wu,Jiajun Zhang
}

Department of Missile Engineering, Ordnance Engineering College, Shijiazhuang, China, 050003

\section{5@qq.com}

Keywords: 3D pringting technique, military equipment, teaching modes, teaching research.

Abstract. Given that the application of 3D printing in the field of education is still in the stage of discussing and studying nowadays, this paper aims at the military educational use of 3D printing as well as military equipment educational use practically, which is based on a brief analysis about the principle of 3D printing and also including military equipment theoretical education and practical teaching. The last part of this paper is about analysising the preoblems existed in the use of 3D printing in military equipment education and then bring about possible solutions.

\section{Definition of 3D printing}

3D printing, i.e. incremental manufacturing, also named as Rapid prototyping technology, is a laminated manufacturing technology through adding materials to different layers on a computer model in order to creating the real stuff, based on the rapid prototyping process of the material accumulation principle.

3D printing is also a form of adding and making technology, which uses Hierarchical processing and superposition forming, i.e. adding material step by step to form the real one.

\section{Principle of 3D printing}

For most of the individuals, speaking of "printing”, printers being able to print documents or photos come up first in our mind. In fact, two-dimensional ink-jet printing technology is similar to some sorts of 3D printing technology. 3D printing uses special equipment named 3D printer ( see from Fig 1) to spray or sinter the material to three-dimensional space, which finally form the item we wanted.

The benefits of the 3D printer lie in two aspects. First of all, it is very accurate, and even if you use the cheapest kind, you will not miss any of the details in the model. Moreover, compared to traditional ways such as casting, stamping and etching, it takes less time to form the real model, especially for those are difficult to build through traditional ways. Basically, there are four main steps in building a real stuff by 3D printer (see from Fig 2), called model building, layering, printing and post processing respectively.

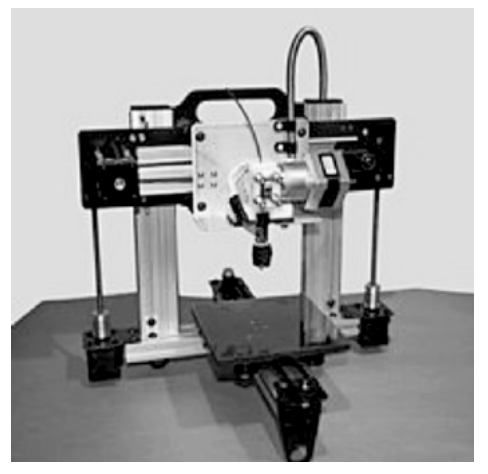

Fig 1 3D Printer 


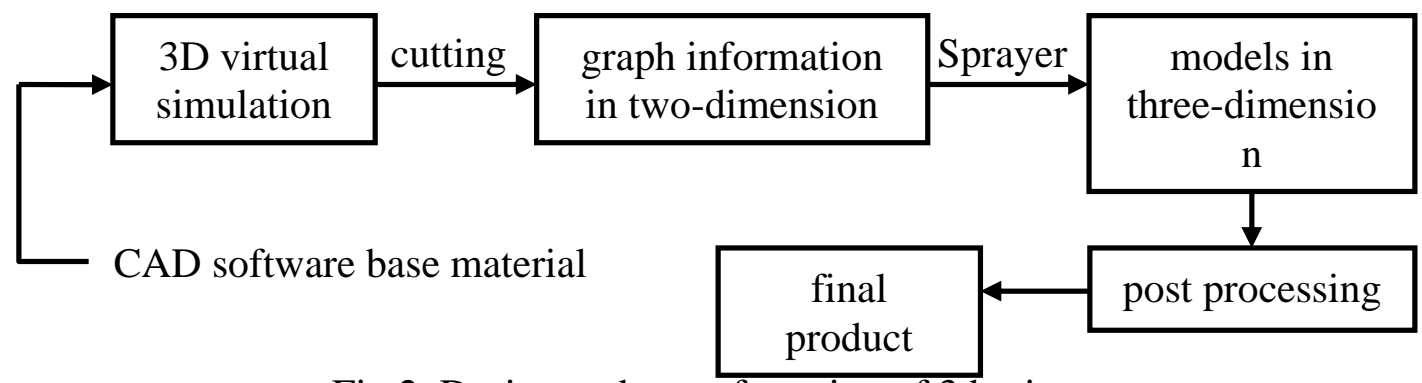

Fig 2 Design and manufacturing of 3d printer

\subsection{Models in three-dimension}

Not only can we do this through professional 3D scanners such as goSCAN, but we can also using DIY scanners like Kinect to get data in three-dimension and then form the model in a digital way. In addition, using modeling software such as Blender, SketchUp, AutoCAD can also build three-dimension digital model. Of course, it will be much easier if there already exists a model built by predecessors and then you can use that directly.

\subsection{Layered cut}

Due to the different way of describing, it is not possible for 3D printer to deal with 3D model directly. After inputting the 3D model into a computer, we need some professional software to handle it, which means that we cut the model into slices whose thickness are depended on the properties of coating material and the size of the printer.

\subsection{Spraying with printing}

There are many ways to use printers to spray or sinter printing supplies into the three-dimensional space based on different principles. One popular way is to spray a layer of glue first, and then put some powder on it repeatedly. Another way is to sinter the model step by step with the help of high energy laser which can melt alloy material.

\subsection{Post process}

After the printing, the model usually has a rough section or mold flash. Therefore, we need post processing to polish our model by curing process, stripping, finishing and coloring etc.

\section{3D Printing in military equipment educational use}

The mainly application of 3D printing are two kinds: one is setting up relative courses, which can offer basic knowledge and skills about 3D printing to design a product in the future; another one is using 3D technology in teaching process to make the class more vivid to improve the quality of teaching. In this paper, we emphasize the last one most.

For military college, military equipment education has two main parts: theory and practice. If we can apply 3D printing technique into both of them, it will have a significant difference in improving teaching quality.

The theoretical part teaching about the specific parameters, basic parts including their structures and principles, which are boring to students. In the past, students pay little attention to these contents due to their lacking of interest, tracking to the lack of actual models. Most of the conditions we rely on pictures to illustrate the principles and structures, resulting in the details cannot be fully shown.

The practical part is mainly about being familiar with the structure of the equipment , learning the fundamental process and being capable of the basic operations. However, lacking sufficient 
equipment , huge loss due to frequent use and the number of students is large in the same group when operating by groups.

3D printing can easily solve these problems. Not only can it change abstract things into real models, contributing to a deep understand to the formula, but it can also build models according to different stages of a stuff, which makes it more intuitive for students to emphasize. Professors can use 3D printers to make teaching aids that can be used to solve the insufficient aids problem.

Nevertheless, every coin has two sides. 3D printing technology also has its limitations. First of all, it will take some time for professors to make those teaching aids because it is usually not that easy to print a model. In addition, we need to find the suitable material for printing. Moreover, accurate 3D printers are expensive, which cannot be affordable for some colleges.

3D printing opens a new world for education and some institutions and organizations are studying how to make it useful in teaching and learning. Not only can students enjoy the benefits made by that newly invented technique, but it can also be used as a way to persuade them to design better equipment, which will make a difference in their further career or study field. The table 1 bellow shows some examples about the usage of 3D printing in different field about teaching.

Table 1 Application Cases of 3D Printing in different educational fields

\begin{tabular}{|c|c|c|}
\hline Number & Subject/Field & Examples/cases \\
\hline 1 & Electron & Making model replacement parts, fixtures and equipment shell, etc \\
\hline 2 & Chemistry & Making 3D molecular models,etc \\
\hline 3 & $\begin{array}{l}\text { Biology and } \\
\text { medicine }\end{array}$ & Printing out molecules, virus, organ, artificial joints or other models \\
\hline 4 & Math & $\begin{array}{l}\text { Printing models based on mathematical equations that are used to solve the } \\
\text { problem of geometric surface and urban design layout, etc }\end{array}$ \\
\hline 5 & Aviation & Printing out the model plane, as the aerodynamic test model \\
\hline 6 & Geograpgy & $\begin{array}{l}\text { Making three-dimensional topographic map, such as demographic figure } \\
\text { visual model }\end{array}$ \\
\hline 7 & Cooking & $\begin{array}{l}\text { To produce food display model, print out the chocolate model, and even } \\
\text { artificial food }\end{array}$ \\
\hline 8 & $\begin{array}{l}\text { Mechanical and } \\
\text { electrical } \\
\text { engineering }\end{array}$ & $\begin{array}{l}\text { Producing prototype according to the design work fast, or gear, connecting rod } \\
\text { and other components can be used directly }\end{array}$ \\
\hline 9 & $\begin{array}{l}\text { Architectural } \\
\text { design }\end{array}$ & Printing out the design work of miniature $3 \mathrm{D}$ model \\
\hline 10 & Archaeology & $\begin{array}{l}\text { Used for rehabilitation in the history of arts and crafts, antique, used to } \\
\text { duplicate the fragile }\end{array}$ \\
\hline 11 & Animation Design & Printing out the $3 \mathrm{D}$ model of works, such as characters, animation role model \\
\hline 12 & Astronomy & Printing the object model according to the observation data \\
\hline 13 & Machenics & $\begin{array}{l}\text { Building bridge models according to the original design as well as doing } \\
\text { mechanics experiments }\end{array}$ \\
\hline
\end{tabular}

\section{Effects about 3D Printing in military equipment educational use}

\subsection{Improve methods used in military equipment education}

3D printing can change abstract definitions into interesting problems in order to help students get a good knowledge of them. Considering that it is impossible for professors to use pictures and models shown on the computer to illustrate the structures and principles directly to their students, it is much more convenient for students to learn through real models made by 3D printers. In addition, traditional ways of making real ones mostly rely on ordnance factory, which takes too much time to update. On the contrary, 3D printing technique makes it possible for more original designs of models 
as well as more suitable for teaching and learning process. Clearly, it is much better for students to learn with a real model in hand.

\subsection{Assistant students to creative design}

Students majored in equipment engineering and architecture can use 3D printer to build their models quickly. Without spending a lot of time making the models by hands, printing directly from their computers using 3D printers is apparently more efficient. For instance, in the theoretical mechanics course, we can design models of the scheme of the structure of all kinds of bridge and print into an object, including achieving the bearing capacity test.

\subsection{Improve students' operative ability and sense of corporation}

Taking the scientific making of the innovation cup activity for example, students design and build their models by themselves, which improves their operation and observation abilities a lot. 3D printing opens a new world for study, making it possible for students to be involved in designing, making and illustrating aspects during their studying and also increasing their passion in both practice and study.

\subsection{Build more desirable and enjoyable study experience}

The main idea about 3D printing is its capability about making virtual digital pictures into real stuff, which helps students interact with it better and also enables students to memory for a relative more time.

\section{Thinking about the application of 3D Printing in military equipment educational use}

Though there are an increasing number of applications of 3D printing technology in education field, there are still some problems remained to be solve, especially in military colleges. Most professors and students know a little about it, let alone application. The followings are some suggestions about how to improve this situation.

\subsection{Teaching application of 3D printing}

As for application, the first thing we need to do is to make sure both professors and students see its benefits. It is not widely used nowadays in equipment education field and only appears in mechanical teaching and research office. Therefore, we should advertise it by lectures or public courses to assure they understand the importance and the advantages.

\subsection{Requirements for professors}

Professors play a dominant role in 3D printing education. Much higher requirement rises for professors to use 3D printing into teaching design to give directions to students that will help them learning better in the future.

\subsection{Conception revolution in teaching field}

In the ancient time, teachers rely most on chalks and notes for their courses. With the development of the new technique, traditional ways of teaching are hit heavily. Whether 3D printing will become the next "subverter" remains to be seen. In order to make it really suitable for teaching and learning, we need to change our conventional concepts of teaching and then make it actually a teaching aid, which is not based on some forced reasons such as "mission" or "creation” . 


\section{References}

[1] Dai Jun,applications of 3D printing technology about the future electrician teaching ideas, Frontier Theory, 2013(4).

[2] Shuming Li,Meng Li,Yimin Yang,Heng Du,Yong Wang,3D printing and computer aided technology application in orthopedic clinical teaching , China Medical Education Technology,2015(29).

[3] Yu Fu,Liping Gao,Lihuan Hou,Lixia Gu,3D printing technology and its enlightenment to the teaching of mechanical modern educational technology,2013(12).

[4] Yan Liang,Li Liang,Teaching applications of Solidworks and FDM combination modes, china modern educational equipment,2015(217).

[5] Yuyang Tong,The application of 3D printing technology in primary and secondary school teaching research,modern educational technology.2013(12). 